FVC decline $\geq 10 \%$ pred in INPULSIS had higher mortality in INPULSIS-ON than patients with FVC decline $<10 \%$ pred.

Conclusion Independent of FVC decline in the first year, most patients had FVC decline $<10 \%$ pred with continued nintedanib for a second year. FVC decline $\geq 10 \%$ pred over 1 year did not predict subsequent FVC decline, but was associated with higher mortality.

Please refer to page A261 for declarations of interest in relation to abstract M29.

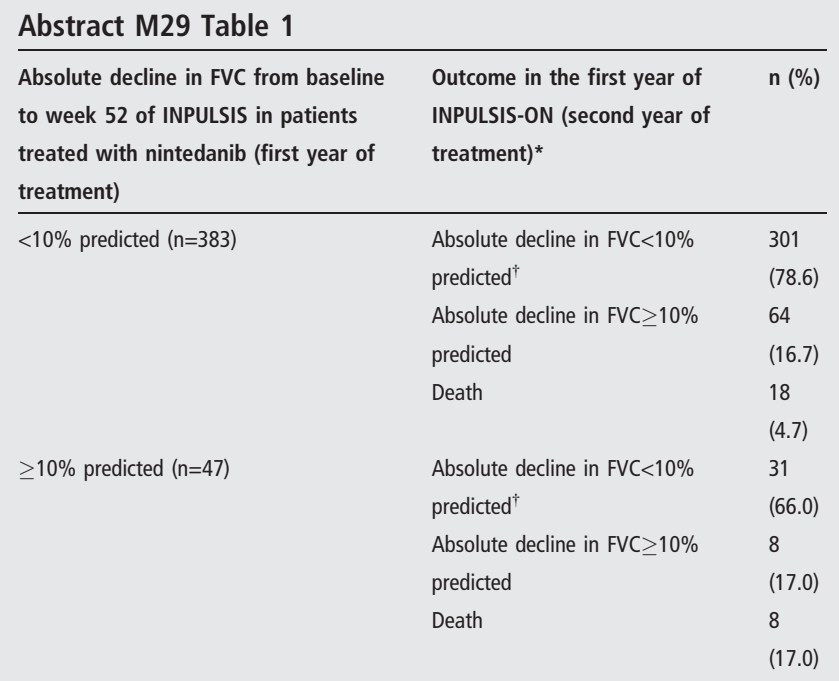

*Patients who discontinued INPULSIS-ON without having an absolute decline in FVC $\geq 10 \%$ predicted or having died were counted in the category "absolute decline in FVC $<10 \%$ predicted". "Includes patients with an increase, no decline, or an absolute decline in FVC $>0 \%$ but $<10 \%$ predicted in the first year of INPULSIS-ON.

\section{M30 EFFECT OF DOSE REDUCTIONS AND/OR INTERRUPTIONS ON THE EFFICACY OF NINTEDANIB IN PATIENTS WITH IDIOPATHIC PULMONARY FIBROSIS (IPF): SUBGROUP ANALYSIS OF THE INPULSIS TRIALS}

${ }^{1}$ TM Maher, ${ }^{2} Y$ Inoue, ${ }^{3} \mathrm{AH}$ Case, ${ }^{4} \mathrm{~W}$ Sakamoto, ${ }^{5} \mathrm{~S}$ Stowasser, ${ }^{6}$ WA Wuyts. ${ }^{1}$ National Institute for Health Research Biomedical Research Unit, Royal Brompton and Harefield NHS Foundation Trust, and National Heart and Lung Institute, Imperial College, London, UK; ${ }^{2}$ Clinical Research Centre, National Hospital Organisation Kinki-Chuo Chest Medical Centre, Osaka, Japan; ${ }^{3}$ Piedmont Healthcare, Atlanta, Georgia, US; ${ }^{4}$ Nippon Boehringer Ingelheim Co. Ltd, Tokyo, Japan; ${ }^{5}$ Boehringer Ingelheim Pharma GmbH and Co. KG, Ingelheim am Rhein, Germany; ${ }^{6}$ Department of Respiratory Medicine, University Hospitals Leuven, Leuven, Belgium

\subsection{6/thoraxjnl-2017-210983.452}

Introduction and Aim The efficacy and safety of nintedanib in patients with IPF were assessed in two replicate Phase III placebocontrolled INPULSIS trials. In both trials, nintedanib reduced disease progression by reducing decline in FVC. The recommended dose of nintedanib was $150 \mathrm{mg}$ bid, but dose reductions to $100 \mathrm{mg}$ bid and treatment interruptions were allowed for the management of adverse events. Following dose reduction, the dose could be re-escalated to $150 \mathrm{mg}$ bid. We assessed whether dose reductions and/or treatment interruptions influenced the effect of nintedanib on reducing FVC decline.

Methods We assessed change from baseline in FVC $(\mathrm{mL})$ at week 52 in subgroups of patients by their last dose $(150 \mathrm{mg}$ bid or $100 \mathrm{mg}$ bid) and whether they had experienced a dose reduction and/or treatment interruption using pooled data from both INPULSIS trials. Patients who prematurely discontinued trial medication but had an FVC value at week 52 were included in the analysis. Analyses were descriptive and based on observed cases.

Results A total of 864 patients were included in the analysis (519 treated with nintedanib, 345 with placebo). Most (75\%) patients did not have a dose reduction or treatment interruption. Mean (SD) changes from baseline in FVC at week 52 in subgroups by dose are shown in the Table. In patients who took nintedanib $150 \mathrm{mg}$ bid as their last dose, absolute mean changes from baseline in FVC at week 52 were $-118 \mathrm{~mL}$ and $-90 \mathrm{~mL}$ in patients who did and did not have any prior dose reduction and/or treatment interruption, respectively. In patients who took nintedanib $100 \mathrm{mg}$ bid as their last dose, mean change from baseline in FVC at week 52 was $-74 \mathrm{~mL}$. These changes were consistent with the decline in FVC observed in the whole nintedanib group $(-89 \mathrm{~mL})$.

Conclusion Pooled data from the INPULSIS trials show that decline in FVC was similar in patients treated with nintedanib irrespective of whether they had dose reductions and/or treatment interruptions. These Results suggest that the dosing regimen used in the INPULSIS trials was effective at reducing disease progression in patients with IPF.

Please refer to page A261 for declarations of interest in relation to abstract M30.

Abstract M30 Table 1 Change from baseline in FVC $(\mathrm{mL})$ at week 52 by dose subgroups in INPULSIS

\begin{tabular}{|c|c|c|c|c|}
\hline & \multicolumn{2}{|c|}{ Nintedanib } & \multicolumn{2}{|c|}{ Placebo } \\
\hline & $\mathrm{N}$ & $\begin{array}{l}\text { Mean } \\
\text { (SD) }\end{array}$ & $\mathbf{N}$ & $\begin{array}{l}\text { Mean } \\
\text { (SD) }\end{array}$ \\
\hline All patients & 519 & $\begin{array}{l}-89 \\
(264)\end{array}$ & 345 & $\begin{array}{l}-203 \\
(293)\end{array}$ \\
\hline $\begin{array}{l}\text { Patients who did not have a dose reduction or treatment } \\
\text { interruption }\end{array}$ & 340 & $\begin{array}{l}-90 \\
(265)\end{array}$ & 309 & $\begin{array}{l}-200 \\
(292)\end{array}$ \\
\hline $\begin{array}{l}\text { Patients who took } 150 \mathrm{mg} \text { bid as last dose and } \\
\text { had } \geq 1 \text { dose reduction and/or treatment interruption }\end{array}$ & 56 & $\begin{array}{l}-118 \\
(251)\end{array}$ & 31 & $\begin{array}{l}-203 \\
(273)\end{array}$ \\
\hline $\begin{array}{l}\text { Patients who took } 100 \mathrm{mg} \text { bid as last dose after } \geq 1 \text { dose } \\
\text { reduction and/or treatment interruption }\end{array}$ & 123 & $\begin{array}{l}-74 \\
(269)\end{array}$ & 5 & $\begin{array}{l}-391 \\
(422)\end{array}$ \\
\hline
\end{tabular}

\section{M31 SAFETY OF COMBINED PIRFENIDONE AND NINTEDANIB IN PATIENTS WITH IDIOPATHIC PULMONARY FIBROSIS}

${ }^{1} \mathrm{KR}$ Flaherty, ${ }^{2} \mathrm{CD}$ Fell, ${ }^{3} \mathrm{JT}$ Huggins, ${ }^{4} \mathrm{H}$ Nunes, ${ }^{5} \mathrm{R}$ Sussman, ${ }^{6} \mathrm{C}$ Valenzuela, ${ }^{7} \mathrm{U}$ Petzinger, ${ }^{8} \mathrm{JL}$ Stauffer, ${ }^{9} \mathrm{~F}$ Gilberg, ${ }^{9} \mathrm{M}$ Bengus, ${ }^{10} \mathrm{M}$ Wijsenbeek. ' University of Michigan, Ann Arbour, US; ${ }^{2}$ University of Calgary, Calgary, Canada; ${ }^{3}$ Medical University of South Carolina , Charleston, US; ${ }^{4}$ Hôpital Avicenne, Paris, France; ${ }^{5}$ Atlantic Health System, Overlook Medical Centre, Summit, US; ${ }^{6}$ Hospital Universitario de La Princesa, Instituto de Investigación Princesa, Madrid, Spain; ${ }^{7}$ Clinipace-Accovion GmbH, Eschborn, Germany; ${ }^{8}$ Genentech Inc., South San Francisco, US; ${ }^{9} \mathrm{~F}$. Hoffman-La Roche Ltd, Basel, Switzerland; ${ }^{10}$ Erasmus University Medical Centre, Rotterdam, The Netherlands

\subsection{6/thoraxjnl-2017-210983.453}

Background Safety data on combined pirfenidone and nintedanib use are limited.

Methods A single-arm, open-label study (NCT02598193) assessed safety and tolerability of 24 weeks' pirfenidone (1602-2403 mg/ day) and nintedanib (200-300 mg/day) in patients with idiopathic pulmonary fibrosis (IPF) with forced vital capacity (FVC) $\geq 50 \%$ and diffusing capacity of the lung for carbon monoxide (DLco) $\geq 30 \%$. Before initiating nintedanib, patients had received pirfenidone for $\geq 16$ weeks and tolerated a stable dose 
Abstract M31 Table 1 Summary of safety profile at the prespecified interim analysis

\begin{tabular}{|l|c|c|c|c|c}
\hline & $\begin{array}{c}\text { Patients with at } \\
\text { least one } \\
\text { TEAE* }^{*}\end{array}$ & $\begin{array}{c}\text { Patients with at } \\
\text { least one TEAE } \\
\text { related to } \\
\text { pirfenidone } \\
\text { only } \\
\mathbf{n}=63\end{array}$ & $\begin{array}{c}\text { Patients with at } \\
\text { least one TEAE } \\
\text { related to } \\
\text { nintedanib only } \\
\mathbf{n}(\%)\end{array}$ & $\begin{array}{c}\text { Patients with at } \\
\text { least one TEAE } \\
\text { relateds to both } \\
\text { pirfenidone and } \\
\text { nintedanib } \\
\mathbf{n}(\%)\end{array}$ \\
\hline All treatment-related TEAEs (total of 330 events)
\end{tabular}

"Each of the patients could have experienced $\geq 1$ treatment-related event, with the potential for

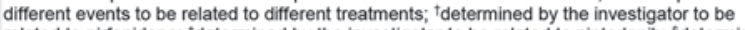
related to pirfenidone; "determined by the investigator to be related to nintedanib; 'sdetermined by the investigator to be related to both pirfenidone and nintedanib

TEAE, treatment-emergent adverse event

of $\geq 1602 \mathrm{mg} /$ day pirfenidone for $\geq 28$ days. Investigators recorded treatment-emergent adverse events (TEAEs), attributing them to pirfenidone, nintedanib, both or neither. Change from baseline FVC, DLco and King's Brief Interstitial Lung Disease (KBILD) score were assessed at 24 weeks. The study is monitored by a data monitoring committee.

Results Eighty-nine patients were enrolled.

A pre-specified interim analysis was conducted once 63 patients (mean age 68.7 years, $85.7 \%$ male) completed $(n=50)$ or discontinued $(n=13) 24$ weeks' combination treatment. Fifty patients had 330 treatment-related TEAEs (Table); 11 patients discontinued due to TEAEs. Two patients had serious treatment-related TEAEs (Table) but none led to death. Final Results for all 89 patients, including change from baseline FVC, DLco and K-BILD score, will be presented at BTS.

Conclusions Combined pirfenidone and nintedanib use for 24 weeks did not reveal a different safety profile to that expected for either treatment alone. Patients had tolerated a stable dose of pirfenidone before initiation of nintedanib, which may explain why investigators attributed more TEAEs to nintedanib than pirfenidone.

Funding F. Hoffmann-La Roche, Ltd./Genentech, Inc.

\section{M32 EFFECT OF PIRFENIDONE ON ALL-CAUSE MORTALITY (ACM) AND FORCED VITAL CAPACITY (FVC) IN IDIOPATHIC PULMONARY FIBROSIS (IPF) PATIENTS WITH LOW FVC AND/OR LOW DLCO: ANALYSIS OF POOLED DATA FROM ASCEND AND CAPACITY}

${ }^{1} \mathrm{SD}$ Nathan, ${ }^{2} \mathrm{U}$ Costabel, ${ }^{3} \mathrm{C}$ Albera, ${ }^{4} \mathrm{KU}$ Kirchgaessler, ${ }^{5} \mathrm{~W}$ Chou, ${ }^{6} \mathrm{PW}$ Noble. ${ }^{1}$ Inova Fairfax Hospital, Falls Church, US; ${ }^{2}$ Ruhrlandklinik, University of Duisburg-Essen, Essen, Germany; ${ }^{3}$ University of Turin, Turin, Italy; ${ }^{4}$ F. Hoffman-La Roche Ltd., Basel, Switzerland; ${ }^{5}$ Genentech Inc., South San Francisco, US; ${ }^{6}$ Cedars-Sinai Medical Centre, Los Angeles, US
Introduction The pivotal trials of the two approved therapies in IPF, pirfenidone and nintedanib, assessed patients with protocol-defined mild to moderate disease. The effect of pirfenidone in patients with more severe lung function impairment warrants further investigation. Pooled Results from ASCEND and CAPACITY studies (NCT01366209, NCT00287729 and NCT00287716) showed a significant reduction at 12 months in the risk of ACM (hazard ratio [HR], 0.52; 95\% CI, 0.31, $0.87)^{1}$ and in decline of percent predicted FVC (\%FVC; $14.8 \%$ vs. $26.3 \%$ patients with $\geq 10 \%$ decline in $\% \mathrm{FVC}$ or death, $\mathrm{p}<0.0001)^{2}$ for patients treated with pirfenidone vs. placebo. We present pooled subgroup analyses from ASCEND and CAPACITY for patients with low baseline\%FVC $(<50 \%)$ and/or low percent predicted diffusing capacity for carbon monoxide $\left(\% \mathrm{DL}_{\mathrm{CO}}<35 \%\right)$ to further inform on treatment effect of pirfenidone in patients with more severe lung function impairment.

Methods ACM was compared using the log-rank test, and HR was estimated using Cox regression. The categorical change in $\%$ FVC was summarised with the percent of patients with $a \geq 10 \%$ absolute decline or death, and treatment comparison was performed using the rank ANCOVA method. Annual rate of FVC decline was estimated using the mixed-effects model.

Results 170 patients (90 pirfenidone, 80 placebo) had low $\%$ $\mathrm{DL}_{\mathrm{CO}}(\mathrm{n}=157)$ or\%FVC $(\mathrm{n}=13)$ at baseline. Treatment with pirfenidone was associated with a $72 \%$ reduction in risk of ACM over 12 months vs. placebo (4 vs. 12 deaths; HR, $0.28 ; 95 \%$ CI, 0.09, 0.86; p=0.018; Table). There was a $56 \%$ relative reduction in the proportion of patients with a ${ }^{3} 10 \%$ absolute decline in $\%$ FVC or death at 12 months vs. placebo $(18.9 \%$ vs. $42.5 \%$; $=0.0038)$. The annual rates of FVC decline were 150 and $278 \mathrm{~mL}$ in the pirfenidone and placebo arms, respectively $(\mathrm{p}=0.003)$.

Conclusions Treatment with pirfenidone resulted in clinically meaningful benefits for ACM and FVC decline in patients with baseline $\%$ FVC $<50 \%$ and/or $\% D_{\mathrm{CO}}<35 \%$. These data suggest that patients with more severe lung function impairment can also benefit from pirfenidone therapy.

\section{REFERENCES}

1. King TE Jr, et al. N Engl J Med 2014;370:2083-2092.

2. Noble PW, et al. Eur Resp J 2016;47:27-30.

Abstract M32 Table 1 ACM and FVC outcomes at 12 months in patients with IPF with low FVC and/or low DLCO at baseline*

\begin{tabular}{lll}
\hline Endpoint at 12 Months & $\begin{array}{l}\text { Patients With Low FVC and/or } \\
\text { Low } \mathrm{DL}_{\mathrm{co}} \\
(\mathbf{n}=170)\end{array}$ & $\begin{array}{l}\text { All Patients } \\
(\mathrm{n}=1247)\end{array}$ \\
\hline $\begin{array}{l}\text { Pirfenidone vs placebo } \\
\text { ACM: HR (95\% Cl) }\end{array}$ & $0.28(0.09-0.86)$ & $0.52(0.31-$ \\
$\begin{array}{l}\text { Pirfenidone vs. placebo: } \\
\geq 10 \% \text { absolute decline in\%FVC or }\end{array}$ & $18.9 \%$ vs. $42.5 \%$ & $0.87)$ \\
death & 150 vs. 278 & $14.8 \%$ vs. \\
Pirfenidone vs. placebo: & $(p=0.003)$ & $26.3 \%$ \\
Annual rate of FVC decline, $\mathrm{mL}$ & $(\mathrm{p}<0.0001)$ \\
\hline
\end{tabular}

*All pirfenidone-treated patients included in these analyses were randomised to receive $2403 \mathrm{mg} /$ day. 
M33 LONG-TERM EFFICACY OF NINTEDANIB IS MAINTAINED IN PATIENTS WITH IDIOPATHIC PULMONARY FIBROSIS (IPF) IRRESPECTIVE OF DOSE: SUBGROUP ANALYSIS OF INPULSIS-ON

${ }^{1} \mathrm{~B}$ Crestani, ${ }^{2} \mathrm{M}$ Kolb, ${ }^{3} \mathrm{~B}$ Wallaert, ${ }^{4} \mathrm{M}$ Quaresma, ${ }^{5} \mathrm{~W}$ Stansen, ${ }^{6} \mathrm{~L}$ Richeldi. ${ }^{7}$ Hôpital Bichat, Pneumologie, Paris, France; ${ }^{2}$ McMaster University, Hamilton, Ontario, Canada; ${ }^{3}$ University Hospital of Lille, Lille, France; ${ }^{4}$ Center for Interstitial and Rare Lung Diseases, Pneumology, Thoraxklinik, University of Heidelberg, and Translational Lung Research Centre Heidelberg, German Centre for Lung Research, Heidelberg, Germany; ${ }^{5}$ Boehringer Ingelheim Pharma GmbH and Co. KG, Ingelheim am Rhein, Germany; ${ }^{6}$ Catholic University of the Sacred Heart, Rome, Italy

\subsection{6/thoraxjnl-2017-210983.455}

Introduction and Aim In the INPULSIS trials, nintedanib reduced the annual rate of decline in FVC versus placebo in patients with IPF $(-113.6$ versus $-223.5 \mathrm{~mL} / \mathrm{year})$. Patients completing the 52 week treatment period could receive openlabel nintedanib in an extension trial (INPULSIS-ON). Patients receiving nintedanib or placebo $150 \mathrm{mg}$ bid at the end of INPULSIS received nintedanib $150 \mathrm{mg}$ bid in INPULSIS-ON; patients receiving nintedanib or placebo $100 \mathrm{mg}$ bid at the end of INPULSIS received nintedanib $100 \mathrm{mg}$ bid or $150 \mathrm{mg}$ bid in INPULSIS-ON, based on patient/investigator discussions. Dose reduction from $150 \mathrm{mg}$ bid to $100 \mathrm{mg}$ bid was allowed to manage adverse events; re-escalation to $150 \mathrm{mg}$ bid was permitted. Our objective was to assess whether dose influenced the effect of nintedanib on FVC decline in INPULSISON.

Methods The annual rate of decline in FVC over 96 weeks in INPULSIS-ON was assessed in subgroups of patients by whether they were treated with nintedanib $150 \mathrm{mg}$ bid only, $100 \mathrm{mg}$ bid only, or both $150 \mathrm{mg}$ bid and $100 \mathrm{mg}$ bid. All available FVC measurements collected at time points between baseline and week 96 were used to calculate FVC decline. These analyses were descriptive and based on a data snapshot in October 2015.

Results A total of 734 patients received nintedanib in INPULSIS-ON: 436 patients (59.4\%) received nintedanib $150 \mathrm{mg}$ bid, 53 patients $(7.2 \%)$ received nintedanib $100 \mathrm{mg}$ bid, and 245 patients $(33.4 \%)$ received both doses. The annual rates of decline in FVC over 96 weeks were -116.4 (8.9) $\mathrm{mL} / \mathrm{year}$, -79.0 (30.1) $\mathrm{mL} /$ year, and $-126.2(11.4) \mathrm{mL} /$ year in patients treated with nintedanib $150 \mathrm{mg}$ bid, $100 \mathrm{mg}$ bid, or both doses, respectively, and were consistent with the annual rate of decline in FVC over 96 weeks in all patients treated with nintedanib $(-117.8[6.8] \mathrm{mL} /$ year$)$.

Conclusion Data from INPULSIS-ON demonstrated that the annual rate of decline in FVC was similar in patients treated with nintedanib $150 \mathrm{mg}$ bid, $100 \mathrm{mg}$ bid, or both doses. The long-term efficacy of nintedanib in reducing disease progression was maintained in patients with IPF who required dose adjustments to manage adverse events.

Please refer to page A262 for declarations of interest in relation to abstract M33.

\section{M34 CARDIOVASCULAR SAFETY OF NINTEDANIB IN SUBGROUPS BY CARDIOVASCULAR RISK AT BASELINE IN THE TOMORROW AND INPULSIS TRIALS}

${ }^{1}$ I Noth, ${ }^{2} \mathrm{M}$ Wijsenbeek, ${ }^{3} \mathrm{M}$ Kolb, ${ }^{4} \mathrm{~F}$ Bonella, ${ }^{5} \mathrm{~L}$ Moros, ${ }^{5} \mathrm{D}$ Wachtlin, ${ }^{6} \mathrm{TJ}$ Corte. ${ }^{1}$ Pulmonary and Critical Care Medicine, University of Chicago, Chicago, US; ${ }^{2}$ Erasmus MC, University Medical Centre, Rotterdam, Netherlands; ${ }^{3}$ McMaster University, Hamilton, Canada; ${ }^{4}$ Interstitial and Rare Lung Disease Unit, Ruhrlandklinik, University Hospital, University of Duisburg-Essen, Essen, Germany; ${ }^{5}$ Boehringer Ingelheim Pharma GmbH and Co.KG, Ingelheim am Rhein, Germany; ${ }^{6}$ Royal Prince Alfred Hospital, Camperdown, New South Wales, Australia

\subsection{6/thoraxjnl-2017-210983.456}

Introduction and Aim Nintedanib is a tyrosine kinase inhibitor, a drug class that may be associated with increased risk of arterial thromboembolic events. The efficacy and safety of 52 weeks' treatment with nintedanib versus placebo in patients with IPF were assessed in the TOMORROW and INPULSIS trials. Patients with myocardial infarction in the previous 6 months, unstable angina in the previous month, or stroke in the previous year were excluded. We assessed the effect of $\mathrm{CV}$ risk at baseline on the CV safety of nintedanib $150 \mathrm{mg}$ bid.

Methods Incidence rates of major adverse CV events (MACE) in subgroups of patients with a history of atherosclerotic CV disease and/or $\geq 1 \mathrm{CV}$ risk factor at baseline (higher $\mathrm{CV}$ risk), and patients with no history of atherosclerotic CV disease and no CV risk factors at baseline (lower CV risk), were analysed using pooled data from the TOMORROW and INPULSIS trials. CV risk factors were defined as hypertension, dyslipidaemia, BMI $\geq 30 \mathrm{~kg} / \mathrm{m}^{2}$, current/former smoking, and diabetes. MACE were based on fatal adverse events included in the system organ classes "cardiac disorders" and "vascular disorders" in MedDRA; events in the subordinate standardised MedDRA query (SMQ) "myocardial infarction"; stroke based on selected preferred terms from the subordinate SMQs "haemorrhagic cerebrovascular conditions" and "ischaemic cerebrovascular

N Patients with

events, $\mathbf{n}(\%)$

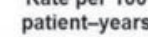

$$
\text { (95\% CI) }
$$

\section{Higher CV risk}

Nintedanib

Placebo

Lower CV risk

Nintedanib

Placebo



451

$23(3.5)$

$15(3.3)$

67

57

$$
\begin{aligned}
& 3(4.5) \\
& 3(5.3)
\end{aligned}
$$

$3.88(2.58,5.84)$

$3.49(2.10,5.79)$

$4.78(1.54,14.82)$

$5.37(1.73,16.65)$
Rate per 100 patient-years $(95 \% \mathrm{Cl})$

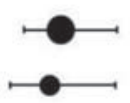

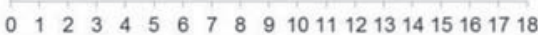


conditions"; and MedDRA preferred terms "sudden death", "cardiac death" and "sudden cardiac death".

Results At baseline, 1107 (89.9\%) patients (656 nintedanib, 451 placebo) had higher CV risk and 124 (10.1\%) patients (67 nintedanib, 57 placebo) had lower $\mathrm{CV}$ risk. In patients with higher CV risk, incidence rates $(95 \% \mathrm{CI})$ of MACE were $3.88(2.58,5.84)$ and $3.49(2.10,5.79)$ per 100 patient-years in the nintedanib and placebo groups, respectively. In patients with lower CV risk, incidence rates $(95 \% \mathrm{CI})$ of MACE were
$4.78(1.54,14.82)$ and $5.37(1.73,16.65)$ per 100 patientyears in the nintedanib and placebo groups, respectively.

Conclusion In pooled data from the TOMORROW and INPULSIS trials, the incidence of MACE was similar between the nintedanib and placebo groups in patients with higher CV risk at baseline and in patients with lower CV risk at baseline.

Please refer to page A262 for declarations of interest in relation to abstract M34. 